\title{
Prevalence of Risk Factors for Hospital-Acquired Venous Thromboembolism in Neurosurgery and Orthopedic Spine Surgery Patients
}

\author{
CHARLA R. FISCHER, MD, ERIK WANG, BA, LEAH STEINMETZ, BA, DENNIS VASQUEZ-MONTES, MS, \\ AARON BUCKLAND, MBBS, FRACS, JOHN BENDO, MD, ANTHONY FREMPONG-BOADU, MD, \\ THOMAS ERRICO, MD \\ Department of Orthopaedics, NYU Langone Orthopedic Hospital, New York, New York
}

\begin{abstract}
Background: Hospital-acquired venous thromboembolisms (HA-VTE) are a significant source of morbidity and mortality in spine surgery patients. The purpose of this study was to review HA-VTE rates at our institution and evaluate the prevalence of known risk factors in patients who developed HA-VTE among both neurosurgical and orthopedic spine surgeries.

Methods: Retrospective chart reviews were conducted of all spine surgery patients from January 1, 2013, to July 31, 2017, to evaluate rates of HA-VTE and prevalence of known HA-VTE risk factors among these patients. Univariate and multivariate logistic regression analysis for categorical variables and independent Student $t$ test for continuous variables were utilized with significance set at $P<.05$.

Results: The overall HA-VTE rate was $0.94 \%$ ( $0.61 \%$ orthopedic, $1.87 \%$ neurosurgery $)$. Patients with VTEs had higher rates of thoracic procedure $(P=.002)$, posterior approach $(P=.001)$, diagnosis of fracture $(P=.013)$ or flatback syndrome $(P=.028)$, neurosurgery division $(P<.001)$, and diagnosis-related group (DRG) of noncervical malignancy $(P=.001)$. Patients with VTEs had lower rates of cervical procedure $(P<.001)$, diagnosis of herniated nucleus pulposus $(P=.006)$ and degenerative disc disease $(P=.001)$, and DRG of cervical spine fusion $(P<.001)$. In the patients who sustained VTE, the neurosurgical patients had higher rates of active cancer $(22.86 \%$ vs $0 \%, P=.004)$ and age $>60(80 \%$ vs $50 \%, P<.001)$, and orthopedic patients had higher estimated blood loss (EBL) (2436 ml vs $1176 \mathrm{~mL}$, $P=.006)$ and rates of anterior-posterior surgery $(22.58 \%$ vs $0 \%, P=.003)$. Neurosurgery department, diagnosis of fracture, and DRG of noncervical malignancy were found to be significant independent risks for developing HA-VTE. Cervical procedures were independently associated with significantly lower risk. Postoperative anticoagulation initiated sooner in neurosurgery patients (postoperative day 1.26 vs $3.19, P<.001$ ).

Conclusions: The overall HA-VTE rate at our institution was $0.94 \%$ ( $0.61 \%$ orthopedic, $1.87 \%$ neurosurgery). In patients who sustained VTE, neurosurgical patients had higher rates of active cancer and age $>60$ years, and orthopedic patients had higher EBL and rates of anterior-posterior surgery. This highlights the different patient populations between the 2 departments and the need for individualized thromboprophylaxis regimens.
\end{abstract}

Level of Evidence: 4.

Complications

Keywords: hospital acquired, venous thromboembolism, prevention

\section{INTRODUCTION}

Venous thromboembolism (VTE) is the number 1 preventable hospital-acquired cause of morbidity and mortality in the United States. ${ }^{1}$ In 2003, over 12 million patients, comprising $31 \%$ of U.S. hospital discharges, were at risk of VTE. ${ }^{2}$ It is estimated that there are nearly 300,000 VTE-related deaths annually in the United States, and approximately twothirds of symptomatic VTE events are hospital acquired. $^{3}$ A 2015 study found that $72 \%$ of VTE patients had emboli that were potentially preventable with prophylaxis. ${ }^{4}$ At the same time, poor adherence to thromboprophylaxis, whether pharmacologic or mechanic, correlates with increased VTE events. Previous studies have reported adherence rates between $38 \%$ and $60 \%$ with American College of Chest Physicians guidelines. ${ }^{5-8}$ Even after a successfully treated episode, subsequent complications affecting the pulmonary, renal, cardiac, and nervous systems may persist for years. ${ }^{9}$ Up to half of lower-extremity deep vein thrombosis (DVT) 
patients develop postthrombotic syndrome and chronic venous insufficiency, struggling with pain, swelling, skin necrosis, and ulceration. ${ }^{10,11}$ Even after a standard course of anticoagulant therapy, one-third of VTE patients experience a recurrence within 10 years of the initial event. ${ }^{10}$ While the highest risk occurs within the first year, patients with a previous VTE remain at increased risk for life. Thus, many VTE patients require long-term anticoagulation to prevent additional clots, and this treatment itself decreases quality of life and increases risk for bleeding episodes. ${ }^{10}$

Another significant challenge presented by VTEs is a resulting increase in health care spending. It is estimated that the total annual health care cost attributable to VTE ranges from $\$ 7594$ to $\$ 16,644$ per patient, up to $\$ 10$ billion annually. These costs are often driven significantly by increased lengths of stay; reoperations and unplanned patient readmissions are generally even more costly.,11,12 There are known risk factors for hospital-acquired VTEs (HA-VTE), but the prevalence of these risk factors is not always reviewed in patients who have sustained DVT or pulmonary embolism (PE). Such factors include genetic (family history, thrombophilic diseases), acquired (age, cancer, obesity, chronic diseases), and transiently acquired (pregnancy, oral contraceptives, trauma, immobilization) variables. $^{10}$

Several studies exist evaluating the prevalence of DVT and PE following orthopedic surgery. ${ }^{13-15}$ Rates of venographic DVT and proximal DVT 1-2 weeks following major orthopedic surgery in patients receiving no prophylaxis are between $40 \%$ and $60 \%$ and $10 \%$ and $30 \%$, respectively. ${ }^{12}$ However, most existing research pertaining to VTEs and orthopedic procedures has explored total hip and knee arthroplasties and hip fractures, and limited data are available on spine surgeries. While there is strong evidence for recommendations on prophylaxis in spine procedures, little information addresses more nuanced details regarding risk factors. ${ }^{12}$ Furthermore, analyses associating categories of diagnoses and procedures in spine surgery with VTE development are lacking. Therefore, this study aimed to review HA-VTE rates at our institution and evaluate the prevalence of known risk factors in patients who developed HA-VTE among both neurosurgical and orthopedic spine surgery patients.

\section{MATERIALS AND METHODS}

\section{Data Source and Inclusion Criteria}

This is a retrospective review of all patients who presented at a large single academic spine center for spinal surgery from January 1, 2013, to July 31, 2017. All patients were included for analysis excluding those with lengths of stay $<1$ day or newborns. Prior approval was obtained from the institutional review board for retrospective patient chart review. Patients were evaluated for rates of HA-VTE as well as prevalence of known HA-VTE risk factors.

\section{Data Collection and Outcome Measures}

Patients were assessed for development of HAVTE. This was defined as an inpatient discharge that was diagnosed with DVT or PE not present on admission or a discharge that was readmitted within 30 days of index discharge with a principal diagnosis of DVT or PE. Patient demographics and risk factors were studied for patients with HA-VTE to compare differences in their prevalence between the orthopedic surgery and neurosurgery divisions. Demographic data collected included gender, age, ethnicity, body mass index (BMI), length of hospital stay, and number of spinal levels involved in surgery. Risk factors evaluated included estimated blood loss, anterior-posterior surgery, active cancer, age $>60$, BMI $>40$, prior VTE, congestive heart failure with ejection fraction $<40 \%$, thrombophilic disease, pulmonary hypertension, restrictive lung disease, smoking history, preoperative neurologic deficit, and intraoperative durotomy. Surgical factors analyzed included procedure level, procedure type, preoperative diagnosis, facility where surgery was performed, surgery department, and diagnosis-related group (DRG). Procedure levels used were thoracic, cervical, and lumbar. Procedure types assessed were fusion, discectomy, posterior approach, and interbody performed. Preoperative diagnoses and surgical DRGs were also evaluated. The prevalence of these factors was compared between patients with and without HA-VTE, between patients undergoing procedures with orthopedic surgery and neurosurgery, and also between patients at different hospital facilities at our institution.

\section{Statistical Analysis}

Statistical analysis was performed using the Statistical Package for Social Sciences, version 23 
(SPSS Inc, Chicago, Illinois). Univariate analysis and multivariate logistic regression analysis for categorical variables and independent Student $t$ test for continuous variables were utilized to evaluate characteristics in association with either development or no development of HA-VTE with a significance set at $P<.05$.

\section{RESULTS \\ Study Sample}

A total of 7156 patients undergoing spine surgery at our institution from January 1, 2013, to July 31, 2017, were studied.

\section{VTE vs Non-VTE: Patient Factors}

The overall HA-VTE rate was $0.94 \%(n=67)$. The HA-VTE rate was $0.61 \%(32 / 5283)$ in orthopedic patients and $1.87 \%(35 / 1873)$ in neurosurgery patients. Patients with VTEs had a significantly higher percentage of individuals with the following factors: thoracic procedure $(P=.002)$, posterior approach $(P=.001)$, diagnosis types of fracture $(P=.013)$ and flatback syndrome $(P=.028)$, surgery performed at Hospital $\mathrm{C}(P<.001)$, neurosurgery division $(P<.001)$, and DRG of noncervical malignancy $(P=.001)$ (Table 1). Patients with VTEs had a significantly lower percentage of individuals with cervical procedures $(P<.001)$, diagnosis types of herniated nucleus pulposus $(P=.006)$ and degenerative disc disease $(P=.001)$, and DRG of cervical spine fusion $(P<.001)$.

Multivariate logistic regression analysis was used to assess for independence of VTE risk factors, controlling for age and gender. The following factors were significant independent risks for developing VTE (Table 2): neurosurgery department (odds ratio [OR] $3.521 \quad[95 \%$ confidence interval (CI) 2.110-5.882], $P<.001$ ), diagnosis of fracture (OR 8.25 [95\% CI 1.471-46.260], $P=.016$ ), and DRG of noncervical malignancy (OR 4.798 [95\% CI 2.845-8.090], $P<.001)$.Cervical procedure (OR 0.343 [95\% CI 0.134-0.879], $P=.026$ ) was independently associated with significantly lower risk of VTE development.

\section{Orthopedic Surgery vs Neurosurgery: Patient Factors}

Comparing patient factors between departments, orthopedic surgery patients had a significantly
Table 1. Patient factor comparisons for venous thromboembolism (VTE) and non-VTE.

\begin{tabular}{|c|c|c|c|}
\hline Factor & $\begin{array}{c}\text { With VTE } \\
(\mathrm{n}=67) \\
\%\end{array}$ & $\begin{array}{c}\text { Without VTE } \\
(\mathbf{n}=7089), \\
\%\end{array}$ & $P$-Value \\
\hline \multicolumn{4}{|l|}{ Procedure level } \\
\hline Thoracic & 11.9 & 3.2 & .002 \\
\hline Cervical & 7.5 & 28.1 & $<.001$ \\
\hline Lumbar & 46.3 & 52.4 & .328 \\
\hline \multicolumn{4}{|l|}{ Procedure type } \\
\hline Fusion & 46.3 & 35.1 & .071 \\
\hline Discectomy & 1.5 & 3.2 & .726 \\
\hline Posterior approach & 71.6 & 51.0 & .001 \\
\hline Interbody performed & 16.4 & 18.3 & .874 \\
\hline \multicolumn{4}{|l|}{ Diagnosis } \\
\hline Degenerative spondylolisthesis & 11.9 & 9.3 & .403 \\
\hline Fracture & 3.0 & 0.2 & .013 \\
\hline Acquired spondylolisthesis & 10.4 & 8.0 & .492 \\
\hline Adolescent idiopathic scoliosis & 4.5 & 5.0 & 1.000 \\
\hline Herniated nucleus pulposus & 6.0 & 18.4 & .006 \\
\hline Hardware failure & 1.5 & 0.2 & .107 \\
\hline Myelopathy & 10.4 & 14.0 & .482 \\
\hline Radiculopathy & 1.5 & 6.4 & .128 \\
\hline Degenerative disc disease & 17.9 & 37.2 & .001 \\
\hline Adjacent segment disease & 1.5 & 1.2 & .569 \\
\hline Flatback syndrome & 1.5 & 0.0 & .028 \\
\hline Kyphosis & 7.5 & 5.7 & .431 \\
\hline Degenerative scoliosis & 7.5 & 5.9 & .596 \\
\hline Stenosis & 14.9 & 18.2 & .632 \\
\hline \multicolumn{4}{|l|}{ Facility } \\
\hline Hospital A & 41.8 & 68.2 & $<.001$ \\
\hline Hospital B & 1.5 & 1.1 & \\
\hline Hospital C & 56.7 & 30.7 & \\
\hline \multicolumn{4}{|l|}{ Gender } \\
\hline Male & 35.8 & 47.7 & .064 \\
\hline Female & 64.2 & 52.3 & \\
\hline \multicolumn{4}{|l|}{ Department } \\
\hline Neurosurgery & 52.2 & 25.9 & $<.001$ \\
\hline Orthopedic surgery & 47.8 & 74.1 & \\
\hline \multicolumn{4}{|l|}{ DRG } \\
\hline Cervical spine fusion & 4.5 & 26.8 & $<.001$ \\
\hline Noncervical malignancy & 38.8 & 9.9 & $<.001$ \\
\hline Noncervical fusion & 32.8 & 39.2 & .316 \\
\hline $\begin{array}{l}\text { Combined anterior-posterior } \\
\text { Fusion }\end{array}$ & 14.9 & 15.2 & 1.000 \\
\hline $\begin{array}{l}\text { Back and neck procedure } \\
\text { without fusion }\end{array}$ & 9.0 & 8.9 & 1.000 \\
\hline
\end{tabular}

higher percentage of individuals with the following factors: lumbar procedure $(P<.001)$; fusion $(P<.001)$ and interbody $(P=.005)$ procedures; diagnosis types of degenerative spondylolisthesis $(P<.001)$, acquired spondylolisthesis $(P<.001)$, adolescent idiopathic scoliosis $(P<.001)$, radicu-

Table 2. Significant independent patient risk factors for venous thromboembolism.

\begin{tabular}{lccr}
\hline Factor & $\begin{array}{c}\text { Odds } \\
\text { Ratio }\end{array}$ & $\begin{array}{c}\text { 95\% Confidence } \\
\text { Interval }\end{array}$ & $\boldsymbol{P - V a l u e ~}$ \\
\hline Neurosurgery department & 3.521 & $2.110-5.882$ & $<.001$ \\
Cervical procedure level & 0.343 & $0.134-0.879$ & .026 \\
Fracture diagnosis & 8.250 & $1.471-46.260$ & .016 \\
$\begin{array}{l}\text { Noncervical malignancy } \\
\quad \text { diagnosis-related group) }\end{array}$ & 4.798 & $2.845-8.090$ & $<.001$ \\
\hline
\end{tabular}


Table 3. Patient factor comparisons between orthopedic surgery and neurosurgery.

\begin{tabular}{|c|c|c|c|}
\hline Factor & $\begin{array}{c}\text { Orthopedic } \\
\text { Surgery } \\
(\mathbf{n}=\mathbf{5 2 8 3}), \\
\%\end{array}$ & $\begin{array}{c}\text { Neurosurgery } \\
(\mathrm{n}=\mathbf{1 8 7 3}) \\
\%\end{array}$ & $P$-Value \\
\hline \multicolumn{4}{|l|}{ Procedure level } \\
\hline Thoracic & 3.3 & 3.0 & .822 \\
\hline Cervical & 26.2 & 33.7 & $<.001$ \\
\hline Lumbar & 55.4 & 43.7 & $<.001$ \\
\hline \multicolumn{4}{|l|}{ Procedure type } \\
\hline Fusion & 37.0 & 29.8 & $<.001$ \\
\hline Discectomy & 1.9 & 7.0 & $<.001$ \\
\hline Posterior approach & 49.8 & 54.1 & .001 \\
\hline Interbody performed & 19.1 & 16.2 & .005 \\
\hline \multicolumn{4}{|l|}{ Diagnosis } \\
\hline Degenerative spondylolisthesis & 11.0 & 4.6 & $<.001$ \\
\hline Fracture & 0.2 & 0.5 & .003 \\
\hline Acquired spondylolisthesis & 9.2 & 4.4 & $<.001$ \\
\hline Adolescent idiopathic scoliosis & 6.4 & 0.8 & $<.001$ \\
\hline Herniated nucleus pulposus & 18.8 & 17.5 & .165 \\
\hline Hardware failure & 0.2 & 0.2 & .525 \\
\hline Myelopathy & 8.9 & 28.5 & $<.001$ \\
\hline Radiculopathy & 7.2 & 4.0 & $<.001$ \\
\hline Degenerative disc disease & 31.4 & 53.8 & $<.001$ \\
\hline Adjacent segment disease & 1.3 & 1.0 & .333 \\
\hline Flatback syndrome & 0.0 & 0.1 & 1.000 \\
\hline Kyphosis & 7.0 & 2.0 & $<.001$ \\
\hline Degenerative scoliosis & 7.2 & 2.1 & $<.001$ \\
\hline Stenosis & 18.6 & 16.8 & .075 \\
\hline \multicolumn{4}{|l|}{ Facility } \\
\hline Hospital A & 87.6 & 12.7 & $<.001$ \\
\hline Hospital B & 0.9 & 1.6 & \\
\hline Hospital C & 11.5 & 85.7 & \\
\hline \multicolumn{4}{|l|}{ Gender } \\
\hline Male & 46.6 & 52.1 & .001 \\
\hline Female & 53.4 & 47.9 & \\
\hline \multicolumn{4}{|l|}{ Diagnosis-related group } \\
\hline Cervical spine fusion & 24.6 & 33.1 & $<.001$ \\
\hline Noncervical malignancy & 10.7 & 7.8 & .002 \\
\hline Noncervical fusion & 37.4 & 44.1 & $<.001$ \\
\hline $\begin{array}{l}\text { Combined anterior-posterior } \\
\text { fusion }\end{array}$ & 19.3 & 3.5 & $<.001$ \\
\hline $\begin{array}{l}\text { Back and neck procedure } \\
\text { without fusion }\end{array}$ & 8.0 & 11.5 & $<.001$ \\
\hline
\end{tabular}

lopathy $(P<.001)$, kyphosis $(P<.001)$, and degenerative scoliosis $(P<.001)$; surgery performed at Hospital A $(P<.001)$; female gender $(P=.001)$; and DRGs of noncervical malignancy $(P=.002)$ and combined anterior-posterior fusion $(P<.001)$ (Table 3$)$. Neurosurgery patients had a significantly higher percentage of individuals with the following factors: cervical procedure $(P<.001)$; discectomy $(P<.001)$ and posterior approach $(P<.001)$ performed; diagnosis types of fracture $(P=.003)$, myelopathy $(P<.001)$, and degenerative disc disease $(P<.001)$; surgery performed at Hospital $\mathrm{C}$ $(P<.001)$; male gender $(P<.001)$; and DRGs of cervical spine fusion $(P<.001)$, noncervical fusion $(P<.001)$, and back and neck procedure without fusion $(P<.001)$.
Table 4. Patient factor comparisons between hospital facilities.

\begin{tabular}{|c|c|c|c|}
\hline Factor & $\begin{array}{c}\text { Hospital A } \\
(\mathrm{n}=\mathbf{4 8 6 3}), \\
\%\end{array}$ & $\begin{array}{c}\text { Hospital C } \\
(\mathrm{n}=2215), \\
\%\end{array}$ & $P$-Value \\
\hline \multicolumn{4}{|l|}{ Procedure level } \\
\hline Thoracic & 2.5 & 5.1 & $<.001$ \\
\hline Cervical & 26.7 & 29.6 & .013 \\
\hline Lumbar & 57.2 & 42.2 & $<.001$ \\
\hline \multicolumn{4}{|l|}{ Procedure type } \\
\hline Fusion & 36.7 & 29.8 & $<.001$ \\
\hline Discectomy & 1.7 & 6.5 & $<.001$ \\
\hline Posterior approach & 48.8 & 56.5 & $<.001$ \\
\hline Interbody performed & 19.6 & 13.7 & $<.001$ \\
\hline \multicolumn{4}{|l|}{ Diagnosis } \\
\hline Degenerative spondylolisthesis & 11.2 & 5.4 & $<.001$ \\
\hline Fracture & 0.1 & 0.5 & .001 \\
\hline Acquired spondylolisthesis & 9.8 & 4.2 & $<.001$ \\
\hline Adolescent idiopathic scoliosis & 4.4 & 6.5 & $<.001$ \\
\hline Herniated nucleus pulposus & 19.1 & 15.7 & $<.001$ \\
\hline Hardware failure & 0.1 & 0.2 & .749 \\
\hline Myelopathy & 9.6 & 22.7 & $<.001$ \\
\hline Radiculopathy & 7.3 & 3.7 & $<.001$ \\
\hline Degenerative disc disease & 32.9 & 45.5 & $<.001$ \\
\hline Adjacent segment disease & 1.2 & 1.2 & 1.000 \\
\hline Flatback syndrome & 0.0 & 0.0 & 1.000 \\
\hline Kyphosis & 5.4 & 6.5 & .069 \\
\hline Degenerative scoliosis & 5.7 & 6.6 & .116 \\
\hline Stenosis & 19.6 & 15.5 & $<.001$ \\
\hline \multicolumn{4}{|l|}{ Gender } \\
\hline Male & 47.0 & 49.2 & .120 \\
\hline Female & 53.0 & 50.8 & \\
\hline \multicolumn{4}{|l|}{ Department } \\
\hline Neurosurgery & 4.9 & 72.5 & $<.001$ \\
\hline Orthopedic surgery & 95.1 & 27.5 & \\
\hline \multicolumn{4}{|l|}{ Diagnosis-related group } \\
\hline Cervical spine fusion & 24.9 & 29.3 & $<.001$ \\
\hline Noncervical malignancy & 8.5 & 14.1 & $<.001$ \\
\hline Noncervical fusion & 38.3 & 40.9 & .038 \\
\hline $\begin{array}{l}\text { Combined anterior-posterior } \\
\text { fusion }\end{array}$ & 20.3 & 4.3 & $<.001$ \\
\hline $\begin{array}{l}\text { Back and neck procedure } \\
\text { without fusion }\end{array}$ & 7.9 & 11.4 & $<.001$ \\
\hline
\end{tabular}

\section{Facility Comparison: Patient Factors}

Patient factors were compared between Hospital A $(\mathrm{n}=4863)$ and Hospital C $(\mathrm{n}=2215)$, excluding Hospital B $(n=78)$ due to a lack of patient volume, which could skew analyses. Patients at Hospital A had a significantly higher percentage of the following factors: lumbar procedure $(P<.001)$; fusion $(P<.001)$ and interbody $(P<.001)$ procedures; diagnosis types of degenerative spondylolisthesis $(P<.001)$, acquired spondylolisthesis $(P<.001)$, herniated nucleus pulposus $(P<.001)$, radiculopathy $(P<.001)$, and stenosis $(P<.001)$; orthopedic surgery division $(P<.001)$; and DRG of combined anterior-posterior fusion $(P<.001)$ (Table 4$)$. Patients at Hospital $\mathrm{C}$ had a significantly higher percentage of the following factors: thoracic $(P<.001)$ and cervical $(P=.013)$ procedures; discectomy $(P<.001)$ and posterior approach $(P<.001)$ performed; diagnosis types of fracture $(P=.001)$, 
Table 5. Characteristics of patients with venous thromboembolism (VTE) in orthopedic surgery and neurosurgery.

\begin{tabular}{lccc}
\hline Factor & $\begin{array}{c}\text { Orthopedic } \\
\text { Surgery }\end{array}$ & Neurosurgery & $\boldsymbol{P}$-Value \\
\hline Demographics, \% & & & \\
Gender (F) & 68.75 & 60 & .611 \\
Average age & 64.80 & 60.59 & .117 \\
Ethnicity, \% & & & .059 \\
$\quad$ White & 65.63 & 70.59 & \\
$\quad$ Black & 18.75 & 23.53 & \\
$\quad$ Hispanic & 15.63 & 0 & \\
$\quad$ Asian & 0 & 5.88 & \\
Average body mass index (BMI) & 31.32 & 28.99 & .112 \\
Average length of stay & 9.66 & 10.74 & .400 \\
No. of surgery levels & 6.56 & 5.68 & .442 \\
VTE risk factors & & & \\
Estimated blood loss, mL & 2436 & 1176 & .005 \\
Anterior-posterior surgery, \% & 22.58 & 0 & .003 \\
Active cancer, \% & 0 & 22.86 & .005 \\
Age >60, \% & 50 & 80 & .001 \\
BMI >40, \% & 6.25 & 2.86 & .603 \\
Prior VTE, \% & 25 & 11.76 & .210 \\
Congestive heart failure with & 3.13 & 0 & .478 \\
$\quad$ ejection fraction <40\%, \% & & & \\
Thrombophilic disease, \% & 3.13 & 0 & .478 \\
Pulmonary hypertension, \% & 3.13 & 0 & .478 \\
Restrictive lung disease, \% & 9.68 & 0 & .335 \\
Smoking history, \% & 51.72 & 51.43 & 1.000 \\
Preoperative neurodeficit, \% & 46.90 & 62.90 & .225 \\
Durotomy, \% & 6.30 & 17.10 & .170 \\
First day of mobilization & 1.56 & 2.09 & .176 \\
$\quad$ postoperative) & & & \\
Invasiveness index score & 19.09 & 15.74 & .196 \\
\hline
\end{tabular}

adolescent idiopathic scoliosis $(P<.001)$, myelopathy $(P<.001)$, and degenerative disc disease $(P<.001)$; neurosurgery division $(P<.001)$; and DRGs of cervical spine fusion $(P<.001)$, noncervical malignancy $(P<.001)$, noncervical fusion $(P=.038)$, and back and neck procedure without fusion $(P<.001)$.

\section{Orthopedic Surgery vs Neurosurgery: Characteristics of Patients With VTE}

Among patients with VTE, there was no difference between orthopedic and neurosurgery patients in terms of patient age, ethnicity, gender, BMI, length of stay, and number of surgical levels (Table 5). When evaluating the prevalence of known risk factors among patients who sustained HA-VTE, orthopedic patients had a higher estimated blood loss (EBL) (2436 mL vs $1176 \mathrm{~mL}, P=.005)$ and percentage undergoing anterior-posterior surgery $(22.58 \%$ vs $0 \%, P=.003)$. Neurosurgery patients had higher rates of active cancer $(22.86 \%$ vs $0 \%$, $P=.004)$ and more patients over the age of $60(80 \%$ vs $50 \%, P<.001)$. Other known risk factors of $\mathrm{BMI}>40$, prior VTE, congestive heart failure with ejection fraction $<40 \%$, thrombophilic disorder, pulmonary hypertension, restrictive lung disease, smoking history, durotomy, preoperative neurologic deficit, first day of mobilization, and invasiveness index score were not significantly different between orthopedic and neurosurgery patients who sustained HA-VTE. The neurosurgery and orthopedic surgery patients who developed VTE had an average number of risk factors of 1.74 and $1.85(P=.759)$, respectively.

When comparing the cohort of patients with HAVTE for differences between the neurosurgery and orthopedic surgery divisions, there were a few differences in practice patterns between the divisions, but these differences were not associated with HA-VTE (Table 6). Orthopedic patients had lower rates of inferior vena cava filter placement $(28.13 \%$ vs $62.86 \%, P=.004)$. All patients of both departments received postoperative anticoagulation, but it was initiated sooner in neurosurgery patients (postoperative day 1.26 vs $3.19, P<.001$ ).

\section{DISCUSSION}

Costs for the management of VTE, the most common preventable, hospital-acquired cause of morbidity and mortality in the United States, are substantial and have increased over time. ${ }^{1,11}$ VTE is estimated to be the second most common cause of excess length of hospital stay and the third most common cause of excess mortality, and readmissions may be up to $48 \%$ more costly than the initial event. ${ }^{11,12}$ Given the economic burden of VTEs and their negative impact on patient quality of life, further exploration on the prevalence of patient risk factors for HA-VTE could improve preventive efforts. Twenty-four percent of VTEs are attributable to hospitalizations following surgery, of which orthopedic procedures make up a significant portion. ${ }^{16}$ Spine surgery in particular lacks analyses associating categories of diagnoses and procedures with VTE development. This retrospective analysis

Table 6. Practice pattern differences between orthopedic surgery and neurosurgery in patients with venous thromboembolism.

\begin{tabular}{|c|c|c|c|c|}
\hline & Factor & $\begin{array}{l}\text { Orthopedic } \\
\text { Surgery }\end{array}$ & Neurosurgery & $P$-Value \\
\hline Prophylaxis and treatment factors & $\begin{array}{l}\text { Rate of inferior vena cava filter placement } \\
\text { Time of anticoagulation initiation (postoperative day) }\end{array}$ & $\begin{array}{l}28.13 \% \\
3.19\end{array}$ & $\begin{array}{l}62.86 \% \\
1.26\end{array}$ & $\begin{array}{r}.007 \\
<.001\end{array}$ \\
\hline
\end{tabular}


aimed to review HA-VTE rates at our institution and evaluate the prevalence of known risk factors in patients who developed HA-VTE among both neurosurgical and orthopedic spine surgery patients. A total of 7156 patients undergoing spine surgery at our institution were included in this study.

We report an overall HA-VTE rate of $0.94 \%$. In the current literature, spine fracture patients have been found to experience VTE at 4 times the rate of other spine surgery patients despite being more likely to receive chemoprophylaxis. ${ }^{17}$ Although our sample size of VTE patients was small, diagnosis of fracture was found to be an independent risk factor for VTE development. While several studies have found a higher VTE risk in anterior approaches, our study did not find anterior approach to be an independent risk for HA-VTE. ${ }^{18,19}$ It is not surprising that patients with malignancy would have a higher HA-VTE risk and that a DRG of noncervical malignancy was a significant independent risk factor for VTE. ${ }^{19,20}$ Cervical procedure levels were associated with significantly lower risk of HA-VTE, likely because of the lower metabolic burden of such operations, allowing patients to mobilize and be discharged more quickly than in thoracolumbar cases. Operation by the neurosurgery department was also an independent HA-VTE risk factor, though this is likely attributable to the significantly higher rates of fracture patients and patients with malignancy seen in the neurosurgery patient population as demonstrated by Table 3 .

Comparing such factors among all patients, between the orthopedic surgery and neurosurgery divisions and also between Hospital A and Hospital $\mathrm{C}$ allowed us to further characterize our findings. There were significant differences in most procedure types, diagnoses, and DRGs. Hospital A and the orthopedic surgery division generally followed similar trends, while Hospital $\mathrm{C}$ and the neurosurgery division followed similar trends. This is likely because the majority of the spine cases performed by the orthopedic surgery division occurred at Hospital A, while those performed by neurosurgery occurred at Hospital C. Overall, comparison between facilities and also between departments generally showed significant differences in the procedures and diagnoses represented by their respective patient populations. These results are consistent with the overall trend that VTEs developed in a higher percentage of neurosurgery patients and in a higher percentage of patients at Hospital C.
Among patients who developed VTEs, orthopedic patients had a higher EBL and percentage of patients undergoing anterior-posterior surgery. Higher intraoperative blood loss is associated with higher rates of VTE in previous studies. ${ }^{17}$ However, EBL was not found to be an independent risk factor in our analysis, and the higher EBL noted in the orthopedic department more likely reflects a higher volume and percentage of deformity procedures performed. We found a higher rate of anteriorposterior surgery in orthopedic surgery patients. Neurosurgery patients had higher rates of active cancer and more patients over the age of 60 . While having a lower average patient age, it is possible that the neurosurgery patients who were over 60 years had more complicated conditions, such as malignancy and trauma, that made them more predisposed to developing VTE compared to the orthopedics patients. There was also no significant difference in first day to mobilization between orthopedic surgery and neurosurgery patients, so patients of both departments were generally mobilized at the same time postoperatively. In addition, there was no significant difference in invasiveness index scores between departments. While the overall average index score for procedures conducted by neurosurgery would likely be higher than that of orthopedics, many of the orthopedic VTE patients underwent extensive adult deformity surgeries involving arthrodesis and instrumentation of numerous levels as opposed to more common procedures that were less invasive, such as laminectomy and discectomy.

We found no significant difference between orthopedic and neurosurgery patients with regard to risk factors for VTE such as BMI $>40$, prior VTE, congestive heart failure with ejection fraction $<40 \%$, thrombophilic disorder, pulmonary hypertension, restrictive lung disease, smoking history, durotomy, or preoperative neurologic deficit. More surgical levels are associated with increased VTE risk, and cardiac risk factors predict increased readmission rates. ${ }^{17}$ The neurosurgery and orthopedic surgery patients who developed VTE had an average number of risk factors of 1.74 and 1.85 , respectively, which reflects the overall low rate of operation on patients with a high risk for VTE.

There were a few notable practice differences between the neurosurgery and orthopedic surgery departments. Orthopedic patients had lower rates of inferior vena cava filter placement, while postoper- 
ative anticoagulation was initiated sooner in neurosurgery patients. These differences most likely highlight differing philosophies between departments about approaching postprocedure anticoagulation as well as timing. While earlier use of VTE prophylaxis has been proposed to better prevent thromboembolic events without a significantly increased risk of bleeding complications, there is no clear consensus on the most effective timing of initiation. ${ }^{21}$ The neurosurgical patients were started on anticoagulation on postoperative day 1, which demonstrates a routine use for starting shortly after surgery. Orthopedic surgery patients were started on postoperative day 3 , which suggests a "wait and see" approach to drain removal and patient mobility. Yet, while neurosurgical patients were started on anticoagulation earlier, there was a higher rate of VTE in their group overall. It may be prudent to further explore prophylaxis regimens in future studies, as these results suggest that expanding on standard prophylaxis for patients at increased risk of VTE, such as trauma and cancer patients, may potentially be beneficial.

Our study had several limitations, mainly its retrospective design with a risk of selection bias and the relatively small sample size for patients who developed HA-VTEs, which may lead to an underestimation of significance for some of the parameters studied. It is also important to recognize that the true incidence of VTE may be higher, with some readmissions for VTE going to outside institutions and also the possibility of asymptomatic VTE. Existing literature suggests that VTEs may be underrecognized following spine surgery and may be as high as $15.5 \%$ in patients without prophylaxis. $^{22}$ This study demonstrates that, at our institution, the true VTE rate is unlikely to be that high. As this analysis focused on a single institution, it also reflects the clinical and operative decision making of our own surgeons with regard to patient selection, surgical procedures, and management. The difference between neurosurgery and orthopedic surgery may additionally be due to practice patterns related to diagnosing VTE. The difference noted may be due simply to a higher likelihood to order ultrasounds on neurosurgery postoperative patients. Our study adds to existing literature pertaining to postoperative VTE in spine surgery by exploring the prevalence of risk factors in greater detail and examining differences between spine disciplines as well as categories of diagnoses and procedures.
Future studies may expand on this work, and a multicenter study may further elucidate the reasons why certain procedures and diagnoses are more associated with HA-VTEs as well as differences between spine disciplines.

\section{CONCLUSIONS}

The overall rate of HA-VTE is $0.94 \%$ for all spine surgery patients at our institution. The HAVTE rate was $0.61 \%$ in orthopedic patients and $1.87 \%$ in neurosurgery patients. In the patients who sustained VTE, the neurosurgical patients had higher rates of active cancer and age $>60$, and orthopedic patients had higher EBL and rates of anterior-posterior surgery. This highlights the different patient populations between the 2 departments and the need for individualized thromboprophylaxis regimens.

\section{REFERENCES}

1. Heit JA, Melton LJ, Lohse CM, et al. Incidence of venous thromboembolism in hospitalized patients vs community residents. Mayo Clin Proc. 2001;76(November):1102-1110. doi: $10.4065 / 76.11 .1102$

2. Anderson FA, Zayaruzny M, Heit JA, Fidan D, Cohen AT. Estimated annual numbers of US acute-care hospital patients at risk for venous thromboembolism. Am J Hematol. 2007;82(9):777-782. doi:10.1002/ajh.20983

3. Heit JA, Cohen AT, Anderson FA. Estimated annual number of incident and recurrent, non-fatal and fatal venous thromboembolism (VTE) events in the US. ASH Аnпи Meet Abstr. 2005;106(11):267a. http://abstracts.hematologylibrary. org/cgi/content/abstract/ashmtg;106/11/910

4. Haut ER, Lau BD, Kraus PS, et al. Preventability of hospital-acquired venous thromboembolism. JAMA Surg. 2015;150(9):912-915. doi:10.1001/jamasurg.2015.1340

5. Suh J, Desai A, Desai A, Cruz J Dela, Mariampillai A, Hindenburg A. Adherence to thromboprophylaxis guidelines in elderly patients with hospital acquired venous thromboembolism: a case control study. J Thromb Thrombolysis. 2017;43(2):172-178. doi:10.1007/s11239-016-1432-6

6. Tapson VF, Decousus H, Pini M, et al. Venous thromboembolism prophylaxis in acutely ill hospitalized medical patients. Chest. 2007;132(3):936-945. doi:10.1378/chest.06-2993

7. Cohen AT, Tapson VF, Bergmann J-F, et al. Venous thromboembolism risk and prophylaxis in the acute hospital care setting (ENDORSE study): a multinational cross-sectional study. Lancet. 2008;371(9610):387-394. doi:10.1016/S01406736(08)60202-0

8. Schleyer AM, Schreuder AB, Jarman KM, LoGerfo JP, Goss JR. Adherence to guideline-directed venous thromboembolism prophylaxis among medical and surgical inpatients at 33 academic medical centers in the United States. Am J Med Qual. 2011;26(3):174-180. doi:10.1177/1062860610382289

9. Di Capua J, Somani S, Kim JS, et al. Hospital-acquired conditions in adult spinal deformity surgery: predictors for 
hospital-acquired conditions and other 30-day postoperative outcomes. Spine (Phila Pa 1976). 2017;42(8):595-602. doi:10. 1097/BRS.0000000000001840

10. Beckman MG, Hooper WC, Critchley SE, Ortel TL. Venous thromboembolism. A public health concern. Am J Prev Med. 2010;38(suppl 4):S495-S501. doi:10.1016/j.amepre.2009. 12.017

11. Fernandez MM, Hogue S, Preblick R, Kwong WJ. Review of the cost of venous thromboembolism. Clin Outcomes Res. 2015;7:451-462. doi:10.2147/CEOR.S85635

12. Geerts WH, Bergqvist D, Pineo GF, et al. Prevention of venous thromboembolism: American College of Chest Physicians Evidence-Based Clinical Practice Guidelines (8th Edition). Chest. 2008;133(suppl 6):381S-453S. doi:10.1378/chest.08-0656

13. Dearborn JT, Hu SS, Tribus CB, Bradford DS. Thromboembolic complications after major thoracolumbar spine surgery. Spine (Phila Pa 1976). 1999;24(14):1471-1476.

14. Rokito SE, Schwartz MC, Neuwirth MG. Deep vein thrombosis after major reconstructive spinal surgery. Spine (Phila Pa 1976). 1996;21(7):853-859. doi:10.1097/00007632199604010-00016

15. West JL III, Anderson LD. Incidence of deep vein thrombosis in major adult spinal surgery. Spine (Phila Pa 1976). 1992;17(suppl 8):S254-S257. http://ovidsp.ovid.com/ovidweb. $\operatorname{cgi}$ ? $\mathrm{T}=\mathrm{JS} \& \mathrm{PAGE}=$ reference $\& \mathrm{D}=$ med $3 \& \mathrm{NEWS}=\mathrm{N} \& \mathrm{AN}$ 1523508

16. Heit JA, Michael O'Fallon W, Petterson TM, et al. Relative impact of risk factors for deep vein thrombosis and pulmonary embolism: a population-based study. Arch Intern Med. 2002;162(11):1245-1248. doi:10.1001/archinte.162.11.1245

17. Cloney MB, Yamaguchi JT, Dhillon ES, et al. Venous thromboembolism events following spinal fractures: a single center experience. Clin Neurol Neurosurg. 2018;174:7-12. doi: https://doi.org/10.1016/j.clineuro.2018.08.030

18. Bouyer B, Rudnichi A, Dray-Spira R, Zureik M, Coste J. Thromboembolic risk after lumbar spine surgery: a cohort study on 325000 French patients. J Thromb Haemost. 2018;16(8):1537-1545. doi:10.1111/jth.14205

19. Kepler CK, McKenzie J, Kreitz T, Vaccaro A. Venous thromboembolism prophylaxis in spine surgery. $J$ Am Acad Orthop Surg. 2018;26(14):489-500. doi:10.5435/JAAOS-D-1700561

20. Oglesby M, Fineberg SJ, Patel AA, Pelton MA, Singh K. The incidence and mortality of thromboembolic events in cervical spine surgery. Spine (Phila Pa 1976). 2013;38(9):E521E527. doi:10.1097/BRS.0b013e3182897839

21. Kim DY, Kobayashi L, Chang D, Fortlage D, Coimbra R. Early pharmacological venous thromboembolism prophylaxis is safe after operative fixation of traumatic spine fractures. Spine (Phila Pa 1976). 2015;40(5):299-304. doi:10.1097/BRS. 0000000000000754

22. Oda T, Fuji T, Kato Y, Fujita S, Kanemitsu N. Deep venous thrombosis after posterior spinal surgery. Spine (Phila Pa 1976). 2000;25(22):2962-2967.

Disclosures and COI: Each institution obtained approval from its local institutional review board to enroll patients in the prospective database, and informed consent was obtained from each patient.

Corresponding Author: Charla R. Fischer, MD, NYU Medical Center, NYU Langone Orthopedic Hospital, Department of Orthopaedic Surgery, 246 East 20th Street, New York, NY 10003. Phone: (646) 356-9415; Fax: (646) 356-9413; Email: Charla.Fischer@nyumc.org.

Published 29 February 2020

This manuscript is generously published free of charge by ISASS, the International Society for the Advancement of Spine Surgery. Copyright (C) 2020 ISASS. To see more or order reprints or permissions, see http://ijssurgery.com. 